УДК 316.7

$10.17213 / 2075-2067-2020-5-84-90$

\title{
ВЛИЯНИЕ КИНЕМАТОГРАФА НА СОЗДАНИЕ ОБРАЗА ГЕРОЯ НАШЕГО ВРЕМЕНИ В МОЛОДЁЖНОМ СЕГМЕНТЕ СОВРЕМЕННОГО РОССИЙСКОГО ОБЩЕСТВА
}

\author{
(C) 2020 г. Н. Н. Капанян
}

\section{Южно-Российский государственный политехнический университет (НПИ) имени М. И. Платова, г. Новочеркасск, Россия}

Целью исследования является соииокультурный анализ современного киноискусства, нацеленного на молодёжную аудиторию, и влияния, которое оно оказывает на формирование образа героя в молодежной среде. С этой целью проводится сравнение советских кинолент с кинолентами современного периода и выделяются основные характеристики популярного героя кино, подверженного различным трансформациям, находящимся в зависимости от этических и эстетических представлений создателей кинолент.

Методологическую базу исследования составляют классические труды по исследованию средств массовой культуры М. Маклюэна, а также научные труды в контексте социологии культуры, рассматривающие социальные функиии кинематографа (М. И. Жабский), влияние кинематографа на процесс социализаџии современной молодежи (М. В. Скрипарь) и на формирование образа героя намего времени (А. В. Бабаева, Й. Хейзинга).

Результаты исследования. Социокультурный анализ состояния современного киноискусства позволил выделить его основные функции в области сочиализации молодежи, в течение которой формируется иееностный образ героя, не задающчего в отличие от советского кинематографа идеологизированный образ, поскольку отсутствие традиционной социальной морали ведет не только к поиску новых путей в развитии кинематографа, но и к превалированию эстетических иенностей над этическими.

Перспективу исследования составляет дальнейший сочиокультурный анализ формирования влияния кинематографа на ичелевую аудиторию - студенческую молодежь.

Ключевые слова: кинематограф; молодежь; социокультурные функциии; герой; соичиализация.

\section{THE INFLUENCE OF CINEMA ON CREATING THE IMAGE OF A HERO OF OUR TIME IN THE YOUTH SEGMENT OF MODERN RUSSIAN SOCIETY}

\section{(C) $2020 \quad$ N. N. Kapanyan}

\section{Platov South Russian State Polytechnic University (NPI), Novocherkassk, Russia}

The purpose of the study is a socio-cultural analysis of contemporary cinema, aimed at a youth audience and the influence it has on the formation of the image of a hero in a youth environment. For this purpose, a comparison of Soviet films with films of the modern period is mad; and the main characteristics of a popular film hero, subject to various transformations, depending on the ethical and aesthetic ideas of the film creators, are highlighted. 
The methodological basis of the study is the classic works on the study of mass culture by M. McLuhan, as well as scientific works in the context of the sociology of culture, considering the social functions of cinema (M.I. Zhabsky), the influence of cinema on the process of socialization of modern youth (M. V. Skripar) and on the formation of the image of the hero of our time (A. V. Babaeva, J. Heizinga).

The results of the study. Sociocultural analysis of the state of modern cinematography made it possible to single out its main functions in the field of youth socialization, during which the value image of the hero is formed, which, unlike Soviet cinema, does not set an ideologized image of the hero, since the absence of traditional social morality leads not only to the search for new ways in the development of cinematography, but also to the prevalence of aesthetic values over ethical ones.

The prospect of the study is a further socio-cultural analysis of the formation of the influence of cinema on the target audience - student youth.

Key words: cinema; youth; socio-cultural functions; hero; socialization.

Введение. Известный современный мыслитель М. Маклюэн отмечал, что «... изменения в соотношении чувств влекут за собой изменения людей. А соотношение чувств меняется тогда, когда одно из них - или телесная, или умственная функция - облекается в конкретную технологическую форму» $[1$, c. 452]. Одной из таких технологических форм является в наше время кинематограф, превратившийся в социальный институт, который не только служит в качестве одного из наиболее популярных средств развлечения, но и выполняет ряд значимых социокультурных функций в современном обществе. Развитие современных коммуникативных технологий не только не привело к исчезновению кинематографа, но значительно расширило его аудиторию, сделав возможным просмотр кинолент в удобное для зрителей время, без обязательного посещения традиционных кинотеатров. Кинематограф значительно расширил жанры киноискусства, что привело к созданию кинолент специально для целевой аудитории. Однако при этом значительно уменьшилось количество кинолент, создаваемых для молодежной аудитории, нацеленных на формирование образа героя, способного стать героем для подражания.

Ведущие методологические подходы к изучению современного кинематографа. Согласно работам российского исследователя кинематографа М.И. Жабского следует выделять такие социальные функции кинематографа, как информационную, коммуникативную, идеологическую (нормативную), политическую (посредническую), релаксационную, интеграционную [2]. Поскольку нас интересует влияние кинематографа на социализацию молодежи и формирование у нее героя нашего времени, то следует обратить внимание на социокультурные функции кинематографа, выделенные М.В. Скрипарем, а именно:

- функцию социального стабилизатора, которая способствует поддержанию общества, резервируя его основополагающие ценности, например, фильм «Неуловимые мстители», который обладал ясной социально-политической ориентацией, закладывая четкие ценностные ориентиры для подрастающего поколения;

- функцию социального катализатора, ускоряющую процесс социализации, однако не всегда создавая позитивные последствия. Так, например, если фильм «Им покоряется небо» способствовал небывалому подъему популярности героев-летчиков среди тогдашней молодежи, то фильм «Игла» и «Интердевочка» «оказали деструктивное воздействие на сознание» молодого поколения;

- функцию социального ингибитора, которая может привентировать (замедлять) негативные социальные явления (агрессия, алкоголизм, наркомания). Так, фильм «На игле» явился своеобразным предупреждением молодым людям о последствиях, к которым ведет употребление наркотических средств [3].

Следует отметить, что кинематограф, предназначенный для молодежи в советский период, был нацелен в первую очередь на фор- 
мирование молодого поколения в контексте коммунистической идеологии, однако нельзя утверждать, что ценности, пропагандируемые советским кинематографом, не несли позитивной ориентации для социализации молодежи, поскольку формировали чувство любви к своей Родине, ответственное отношение к учебе, своим профессиональным обязанностям, уважительное отношение к старшему поколению и показывали героев, которые могли служить примером для молодых людей. Возможно, именно с этим и связано то, что в настоящее время во многих исследованиях фиксируется растущий интерес к кинематографу советского периода. Так, например, в исследовании, осуществленном М. Правдиной в контексте определения рецепции советского кино современными зрителями, отмечается растущий интерес к фильмам, созданным в советский период. В исследовании были использованы глубинные интервью (всего 25) с респондентами, проживающими в различных регионах России (Москва, Самара, Ростов-на-Дону, Архангельск, Новосибирск), а также анализ зрительских комментариев, размещенных в Интернете. Среди качеств, которые привлекают зрительский интерес к советскому кино, были выделены следующие характеристики: качественность, доброта, душевность, позитивность, правдоподобность, интеллектуальность. Несмотря на предубежденность к советскому кинематографу, формируемую при помощи средств СМИ, большинство зрителей в советском кино «привлекает искренность и идейность, даже если это «связано с пропагандистской функцией кино» [4, с. 115].

Между тем для современной ситуации характерен конфликт традиций и инноваций, последние связаны, прежде всего, с освоением и интерпретацией западных кинематографистов, которые зачастую сводятся к механическому копированию голливудских тенденций и технологий 5-10-летней давности. Как подчеркивает И.В. Муравьева, режиссеры, не ограниченные прежней социальной моралью, ищут сегодня особые пути, позволяющие развивать современный кинематограф для молодежи в соответствии с западными ценностями, в котором можно выделить три основные разновидности:

- традиционные, продолжающие эволюцию советского кинематографа, где в цен- тре событий находится молодой человек со своими проблемами и надеждами, характерными для юношеского возраста. По сути, новшество проявляется только в переносе проблем в новые социокультурные условия, где и происходит формирование героя нашего времени. В качестве значимого примера можно привести фильм «Розыгрыш» (режиссер А. Кудиненко), который является ремейком известного фильма В. Меньшова, снятого в 1976 году. Так же, как и в старом фильме, в основе сюжета находится конфликт между учеником и учительницей (в новом варианте практиканткой), в который постепенно вовлекаются все герои картины. Новым представляется показанная ориентация молодежи на достижение успеха любой ценой, для чего, казалось бы, воспитанные и послушные подростки готовы пойти на подлость и предательство традиционных принципов морали;

- ко второму типу можно отнести кинофильмы, использующие в качестве образца для подражания «голливудские стандарты», например, фильм Е. Соколова «Тайна Заборского омута», где главный герой переносит психологическую травму после встречи с речным монстром, приведшую к формированию водофобии. Трагедия юноши заключается в том, что он испытывает недоверие со стороны близкого круга общения, но в финале ему удается выловить монстра и тем самым отстоять свое «лицо» и стать спасителем всех остальных людей от речного монстра. Однако фильм, снятый в духе картин «для семейного просмотра», показал явное несовпадение типичной «американской истории» с самобытностью российских персонажей;

— третий тип кинолент с героем-юношей является своеобразным миксом фильмов «для семейного просмотра», адаптированных к западному кинематографу, и картин, продолжающих традиции советского киноискусства. В качестве примера можно привести фильм А. Суриковой «Тайна “Волчьей пасти”», основной сюжетной линией которого становятся приключения детей моряков Черноморского флота, оказавшихся вовлеченными в военную операцию по обезвреживанию банды террористов. Атмосфера картины в целом совпадает с работами кинематографистов советского периода, рисующих беззаботное детство юных героев-пионеров, которые стре- 
мятся быть достойными своих отцов. При этом определенные речевые обороты, а также повседневная активность молодых людей (например, торговля на пляже варениками своего собственного производства) показывают, что герои существуют в постсоветское время. Наряду с историей подростков в картине показываются сюжетные линии взрослых персонажей, что позволяет фильму быть интересным для разновозрастной аудитории. Данная картина, с одной стороны, продолжает традицию кинофильмов для юношества советского периода, но, с другой, сюжетные линии взрослых героев картины копируют тенденции западных фильмов.

Основные тенденции в развитии кинематографа для молодежи. Проведенный анализ основных методологических подходов к исследованию современного состояния кинематографа позволил выделить три наиболее видимых тренда в создании кинолент для молодого поколения, которые в значительной степени демонстрируют стремление к избеганию морализующего компонента, где зачастую возникает преобладание эстетики над этикой. Анализируя данное соотношение в современном кинематографе, Н.Н. Губанков полагает, что «... теоретическое и практическое решение проблемы взаимоотношений этического и эстетического в конечном итоге всегда являются результатом прямого или косвенного выражения функционирования морали и искусства в условиях конкретной социальной действительности, выражения социальных и философских позиций мыслителя, художника» [5, с. 56].

В ходе социокультурного развития общества происходит переоценка ценностей, отражаясь на переосмыслении образа юного героя, меняется отношение к нему как к «культовому» герою. Модификации интонаций киноповествования и характеристика образа героя напрямую зависят от современного взгляда автора и от его переоценки героев прошлых лет. В качестве примера можно привести всем известного героя Тимура из не менее известного произведения «Тимур и его команда». Первая киноверсия данного произведения появилась в 1940 г. (режиссер А. Разумный), где был воспет образ смелого и справедливого юноши, которой стал героем для подражания для нескольких поколений юных людей. Экранизация повести, снятая в 1970 году, весьма приближенная к первоисточнику, тем не менее, показывает уже иного героя, не столь однозначного, как ранее, конечно, достойного подражания, но уже без прежней фанатичности. В 2004 году с выходом кинокартины «Тимур и его команда» (режиссер И. Масленникова) происходит «смерть» героя как культового персонажа и героя для подражания, чему способствует ироничность, с которой режиссер относится к своему герою, и некоторая насмешливость в воссоздании времени, когда действовал герой повести. Это во многом связано и с ранее упомянутым преобладанием эстетического начала над этическим, что является характерным трендом современного киноискусства, поскольку, стремясь к своему собственному самовыражению, современные режиссёры нередко игнорируют этические ценности, то есть происходит отторжение возможности взаимодействия с тем, «что является, с его точки зрения, чуждым и внешним для искусства» [6, с. 71].

Одним из значимых факторов развития современного киноискусства является его зависимость от так называемой культурной агрессии, которая характеризуется повышенным использованием сцен, связанных с насилием, что привело к созданию «особого культурного героя - Homobelli, основными характеристиками которого становится деструктивность и изменчивость. Как отмечает А.В. Бабаева, «чем быстрее меняется герой, тем больше он отходит от традиции; чем больше он проявляет свою агрессию по отношению к жизни, обстоятельствам, обществу, другим людям, тем он больше привлекает внимание реципиента» [7, с. 127]. В качестве примера она приводит всемирно известный сериал «Игра престолов», где главная героиня сериала Дейнерис Таргарен говорит по поводу тех, кто еще не определил свое место в новой для них реальности: «У них есть выбор: либо они живут в моем новом мире, либо они могут умереть в своем старом», что, по мнению А. Бабаевой, соотносится с идеей О. Шпенглера о том, что «человек - это хищный зверь» [7].

Современное кино, отказываясь от установок на поддержание базовых моральных 
ценностей, зачастую занимает позицию отстраненного наблюдателя, взгляда со стороны на окружающую действительность, что в конечном итоге ведет к отказу от авторства в традиционном его понимании. Так, например, такую позицию можно заметить у авторов двух известных кинолент - «Игры мотыльков» и «Возвращение». В первом из упомянутых фильме речь идет о парнегитаристе, который в силу определенных обстоятельств оказывается в тюрьме, во втором рассматривается извечная тема «отцов» и «детей». Несмотря на несовпадение сюжетных линий, в обеих лентах ощущается некоторая неясность, отстранённость авторской позиции. Но, если в случае с «Возвращением» в контексте его стилистических особенностей данный принцип режиссера представляется весьма органичным, то в «Играх мотыльков» неясность авторской позиции оставляет ощущение недосказанности и формирует неопределённость в восприятии главного героя. Между тем, по мнению всемирно известного ученого Й. Хейзинга, каждое общество испытывает потребность в своих героях, поскольку в повседневности должно происходить нечто героическое, что нарушает привычный порядок и дает людям моральные ориентиры и примеры высокого служения [8].

Пренебрежение базовыми ценностями, излишняя ироничность по отношению к главному герою, намеренно декларативная позиция авторов, при которой обесценивается все и вся, приводит к тому, что с экрана исчез герой, адекватный восприятию молодых людей в качестве героя для подражания. Все более популярным становится «антигерой» - человек, который ради достижения своей цели способен на антисоциальные поступки и действия. При этом он обладает ценными для молодежи качествами: смелостью, уверенностью в себе, способностью на определенную жертвенность ради друга, решительностью, привлекательными физическими характеристиками. В этом отношении восприятие киногероя во многом отличается исходя из демографических характеристик индивида его принадлежностью к тому или иному поколению. Так, согласно социологическим опросам, проведенным во всероссийском масштабе, у респондентов, относящихся к возрастной группе 18-30 лет, главный герой всенародно любимого сериала «Семнадцать мгновений весны» Штирлиц был поставлен на третье место, у тех же, кто старше 45, он был поставлен на первое место. Самым популярным героем среди молодежи оказался былинный персонаж из полнометражного мультипликационного фильма Илья Муромец, второе место было отдано Саше Белому, главному герою из сериала «Бригада», у поколения старше 45 данный герой получил одобрение только у $2 \%$ респондентов. Эти данные говорят о том, что кино, предназначенное для молодого зрителя, должно обладать своей спецификой, в том числе и в выборе главного героя, поскольку все меньшее уважение вызывают такие качества героя, как скромность, душевность, отзывчивость [9].

Исходя из того, что представление о герое расходится в разнопоколенческих группах, ряд современных ученых предпринимают попытки по типологизации героя нашего времени. Так, А.Е. Акимов выделяет в «кодексе героя» такие характеристики, как:

- стремление к достижению поставленной цели, где есть место подвигу;

- цельность натуры, в которую входят душевная и физическая стойкость;

- умение противостоять негативным обстоятельствам и силам, в том числе существующему в обществе консерватизму;

- стремление помочь людям, повлиять на их отношение к окружающему миру [10].

Что касается образа героя в кино, то наиболее удачной классификацией на сегодняшний день нам представляется выделение И. В. Троцук и М.В. Субботиной следующих типов киногероя: герой-воин, герой-спасатель, герой-благотворитель, герой-вдохновитель, герой-авантюрист, герой-демонстратор. Проведя эмпирическое исследование в рамках данной классификации с использованием контент-анализа и методики неоконченных предложений, авторы исследования разработали инструментарий, который позволил бы выявить «представления о героях и героизме в целом, но содержал блок, посвящённый героям в кинематографе - для сравнения представлений о реальном герое и киногерое» $[11$, с. 150]. Анализ фильмов, наиболее успешных в российском прокате (всего 15 
фильмов), показал, что в них присутствует 8 героев-воинов, 4 героя-спасателя, 5 героевблаготворителей, 4 героя-вдохновителя и 4 героя-авантюриста, причем не наблюдается совпадений в контексте получения различных кинопремий, где наибольшее количество премий получил тип героя-авантюриста. Анализ отношения к киногероям показал, что среди молодых людей преобладает, скорее, герой-вдохновитель, а не герой-воин [11, c. 155]. Однако настораживает тот факт, что таких героев молодые люди видят преимущественно среди героев зарубежных фильмов («Аватар», «Назад в будущее», «Хатико», «Пила» и др.).

Согласно проведенному нами опросу среди студентов 1-2-х курсов (общее количество респондентов составило 147) предпочтение среди российских фильмов последних лет было отдано таким фильмам, как «Экипаж», «Лед», «Движение вверх»: их посмотрело 124 человека из 147. Однако практически все (143) студенты отметили, что в основном смотрят зарубежные фильмы, так как «они более интересные и динамичные», главный герой «мало сомневается», «не занудствует в рассуждениях», «справляется с любыми сложностями», «всегда выходит победителем», то есть согласно ранее приведенной классификации, наиболее востребованным героем среди студентов становится «геройвдохновитель».

Заключение. Таким образом, на основании проведенного социокультурного анализа состояния современного кинематографа для молодежи можно заключить, что в современном российском киноискусстве существует своеобразный дефицит героя, который мог бы служить примером для молодых людей в процессе их социализации. Ориентация на голливудскую модель фильмов «для семейного просмотра», с одной стороны, означает размывание тематических сюжетных границ фильмов, предназначенных для молодежи, с другой - не дает героя, который стал бы воплощением как традиционных ценностей, характерных для русской культуры, так и инновационных качеств, востребованных современным социокультурным развитием нашего общества.

\section{Литература}

1. Маклюэн M. Галактика Гутенберга: Становление человека печатающего. - М.: Академический Проект: Фонд «Мир», 2005.

2. Социология и кинематограф / Под общ. ред. Жабского М.И. - М., 2012.

3. Скрипарь М.В. Воздействие манипулятивных технологий кинематографа на процесс социализации и формирование ориентаций молодежи. - Чита, 2009.

4. Правдина М. Советское кино как объект современной культурной рецепции и зрительской привязанности // Вестник общественного мнения. - 2019. - №2 (100). - С. 114-127.

5. Губанков Н.Н. Этические ценности в системе художественной культуры // Искусство и эстетическая культура: Сб. научных трудов. - СПб.: СПГИТМиК, 1992.

6. Безносов В.Г. О диалектике нравственного и эстетического в художественной культуре (культурологический аспект) // Искусство и эстетическая культура: Сб. научных трудов. - СПб.: СПГИТМиК, 1992.

7. Бабаева А.В., Шмелева Н.В. Homo Belli и национальная безопасность: к вопросу о культурной агрессии // Вестник Минского университета. - 2016. - №1-2. - С. 125-135.

8. Хейзинга Й. Героизм // В тени завтрашнего дня. - М.: ООО «Издательство АСТ», 2004. - C. 453-463.

9. Рейтинг героев [Электронный реcypc] — Режим доступа: https://bd.fom.ru/ report/whatsnew/press_r91209.

10. Герой нашего времени. Исследование ВЦИОМ [Электронный ресурс] Режим доступа: https:/gtmarket.ru/news/ culture/2007/10/02/2203.

11. Акимов A.Е. Физика героизма духа // Три ключа. Педагогический вестник. - Выпуск 8. - С. 14-16.

12. Троиук И.В., Субботина М.В. Оценка влияния кинематографа на социальные представления о героизме: апробация одного подхода // Communicology. — 2018. - Т. 6. №4. - C. 140-158.

\section{References}

1. Makljujen M. Galaktika Gutenberga: Stanovlenie cheloveka pechatajushhego [The Gutenberg Galaxy: The formation of the print- 
ing man]. - Moscow: Akademicheskij Proekt: Fond «Mir», 2005.

2. Sociologija i kinematograf [Sociology and cinema] / In Zhabskiy M. I. (eds.). - Moscow, 2012.

3. Skripar' M.V. Vozdejstvie manipuljativnyh tehnologij kinematografa na process socializacii i formirovanie orientacij molodezhi [Influence of manipulative technologies of cinema on the process of socialization and formation of youth orientations]. - Chita, 2009.

4. Pravdina M. Sovetskoe kino kak obekt sovremennoj kul'turnoj recepcii i zritel'skoj privjazannosti [Soviet cinema as an object of modern cultural reception and audience attachment]// Vestnik obshhestvennogo mnenija [Bulletin of public opinion]. — 2019. — №2(100). Pp. 114-127.

5. Gubankov N.N. Jeticheskie cennosti v sisteme hudozhestvennoj kul'tury [Ethical values in the system of artistic culture] // Iskusstvo i jesteticheskaja kul'tura: Sb. nauchnyh trudov [Art and aesthetic culture: Collection of scientific papers]. - Saint-Petersburg: SPGITMiK, 1992.

6. Beznosov V.G. O dialektike nravstvennogo $\mathrm{i}$ jesteticheskogo $\mathrm{v}$ hudozhestvennoj kul'ture (kul'turologicheskij aspekt) [On the dialectics of moral and aesthetic in artistic culture (cultural aspect)] // Iskusstvo i jesteticheskaja kul'tura: Sb. nauchnyh trudov [Art and aesthetic culture:
Collection of scientific works]. - Saint-Petersburg: SPGITMiK, 1992.

7. Babaeva A.V., Shmeleva N.V. Homo Belli i nacional'naja bezopasnost': $k$ voprosu o kul'turnoj agressii [Homo Belli and national security: on the issue of cultural aggression]// Vestnik Minskogo universiteta [Bulletin of the Minsk University]. — 2016. — №1-2. Pp. 125-135.

8. Hejzinga J. Geroizm [Heroism] // V teni zavtrashnego dnja [In the shadow of tomorrow]. - Moscow: OOO «Izdatel'stvo AST», 2004. - Pp. 453-463.

9. Rejting geroev [Rating of heroes] [Jelektronnyj resurs] — URL: https://bd.fom.ru/report/whatsnew/press_r91209.

10. Geroj nashego vremeni. Issledovanie VCIOM [Hero of our time] [Jelektronnyj resurs] — URL: https://gtmarket.ru/news/culture/2007/10/02/2203.

11. Akimov A.E. Fizika geroizma duha [Physics of heroism of the spirit] // Tri kljucha. Pedagogicheskij vestnik [Three keys. Pedagogical Bulletin]. - Issue 8. - Pp. 14-16.

12. Trocuk I.V., Subbotina M.V. Ocenka vlijanija kinematografa na social'nye predstavlenija o geroizme: aprobacija odnogo podhoda [Evaluation of the influence of cinema on social representations of heroism: approbation of one approach] // Communicology. — 2018. Vol.6. - №4. - Pp. 140-158.

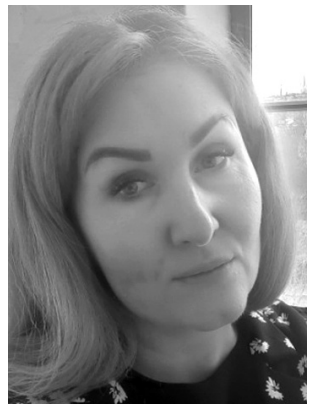

Капанян Нина Николаевна - аспирант, старший преподаватель кафедры «Иностранные языки» Южно-Российского государственного политехнического университета (НПИ) имени М.И. Платова.

Kapanyan Nina Nikolayevna - Postgraduate, Senior Lecturer of the Department «Foreign Languages», Platov South Russian State Polytechnic University (NPI).

346428 , г. Новочеркасск, ул. Просвещения, 132 132 Prosveshcheniya st., 346528, Novocherkassk, Russia

E-mail: ninakapanyan@rambler.ru 